\title{
Correction to: Human Interaction, Emotion and Sustainability: Designing Wooden Children's Furniture
}

Cristina Salvador

\author{
Correction to: \\ Chapter "Human Interaction, Emotion and Sustainability: \\ Designing Wooden Children's Furniture" in: \\ F. Rebelo and M. M. Soares (Eds.): Advances in Ergonomics \\ in Design, AISC 777, \\ https://doi.org/10.1007/978-3-319-94706-8_63
}

In the original version of the book, acknowledgments section has been included in chapter "Human Interaction, Emotion and Sustainability: Designing Wooden Children's Furniture". The correction chapter and the book have been updated with the change.

\footnotetext{
The updated online version of this chapter can be found at https://doi.org/10.1007/978-3-319-94706-8_63 